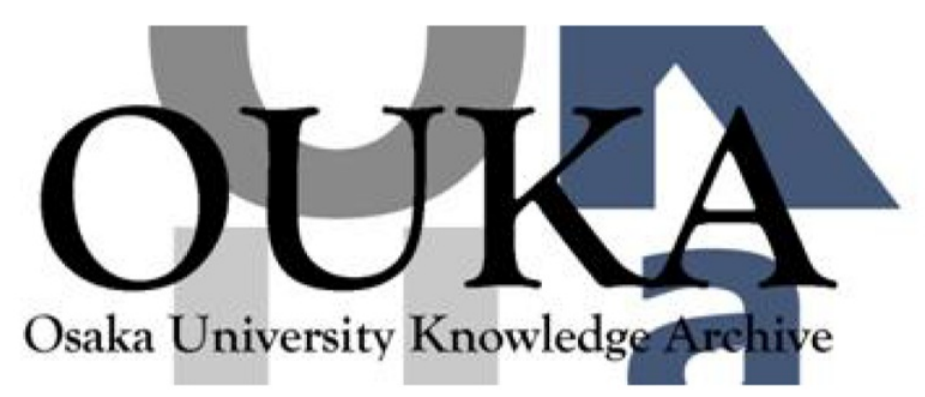

\begin{tabular}{|c|l|}
\hline Title & $\begin{array}{l}\text { Liquid crystalline phthalocyanines as a self- } \\
\text { assembling organic semiconductor for solution- } \\
\text { processing thin film devices }\end{array}$ \\
\hline Author(s) & Miyake, Y.; Hori, T.; Yoshida, H. et al. \\
\hline Citation & $\begin{array}{l}\text { Proceedings of SPIE - the International Society } \\
\text { for Optical Eng ineering. 7955 p. 795505-1- } \\
\text { p. 795505-8 }\end{array}$ \\
\hline Issue Date & $2011-02-02$ \\
\hline oaire:version & VoR \\
\hline URL & https://hdl. handle. net/11094/75930 \\
\hline rights & \\
\hline Note & \\
\hline
\end{tabular}

Osaka University Knowledge Archive : OUKA

https://ir. Library. osaka-u. ac. jp/

Osaka University 
Invited Paper

\title{
Liquid Crystalline Phthalocyanines as a Self-Assembling Organic Semiconductor for Solution-Processing Thin Film Devices
}

\author{
Y. Miyake ${ }^{\mathrm{a}, \mathrm{b}}$, T. Hori ${ }^{\mathrm{b}}$, H. Yoshida ${ }^{\mathrm{b}}$, H. Monobe ${ }^{\mathrm{a}}$, A. Fujii ${ }^{\mathrm{b}}$, M. Ozaki*b ${ }^{*}$ and Y. Shimizu* ${ }^{\text {a }}$ \\ ${ }^{a}$ Synthetic Nano-Function Materials Group, Research Institute for Ubiquitous Energy Devices, \\ National Institute of Advanced Industrial Science and Technology, Kansai Center (AIST-Kansai), \\ Midorigaoka, Ikeda, Osaka 563-8577, JAPAN; \\ ${ }^{\mathrm{b}}$ Division of Electrical, Electronic and Information Engineering, Graduate School of Engineering, \\ Osaka University, 2-1 Yamadaoka, Suita, Osaka, 565-0871, JAPAN
}

\begin{abstract}
A liquid crystalline phthalocyanine semiconductor, $1,4,8,11,15,18,22$, 25-hexahexylphthalocyanine $\left(\mathrm{C} 6 \mathrm{PcH}_{2}\right)$ was studied on the drift mobility of charged carriers by a Time-Of-Flight (TOF) method. It was found that this compound exhibits an ambipolar nature for charge transport and the hole and electron mobilities were determined to be in the order of $10^{-1} \mathrm{~cm}^{2} \mathrm{~V}^{-1} \mathrm{~s}^{-1}$ for polydomain films of the hexagonal disordered columnar $\left(\mathrm{Col}_{\mathrm{hd}}\right)$ mesophase. This is comparable to that of the octyl homologue $\left(\mathrm{C} 8 \mathrm{PcH}_{2}\right)$ reported by Hanna et al. However, $\mathrm{C} \mathrm{PcH}_{2}$ did not show any tendency to form the homeotropic alignment between ITO-coated glass substrates, though $\mathrm{C} 8 \mathrm{PcH}_{2}$ so clearly and easily does. Clear decay curves of the transient photocurrents could be obtained in TOF measurements even for polydomain films of the crystalline solid phase to give a strongly temperature-dependent mobility of holes which reaches to $1.1 \mathrm{~cm}^{2} \mathrm{~V}^{-1} \mathrm{~s}^{-1}$ at room temperature (RT) as the temperature goes down, whilst the electron mobility slightly increases to be $0.5 \mathrm{~cm}^{2} \mathrm{~V}^{-1} \mathrm{~s}^{-1}$ at RT. This compound could easily form thin films by spin-coating technique with the toluene solution and a simple bulk-heterojunction thin film solar cell was fabricated to give a good performance such as $3.1 \%$ of power conversion efficiency and $>70 \%$ of external quantum efficiency.
\end{abstract}

Keywords: liquid crystalline semiconductor, phthalocyanine, carrier mobility, printed electronics, organic solar cell

\section{INTRODUCTION}

Organic electronics is nowadays one of the most interesting and important research fields for ubiquitous electronic devices with much expectation that it could realize light-weight and flexible electronic devices. Recent trend of researches have insisted the solution processing of organic thin film devices such as OLED ${ }^{[1]}$, OFET ${ }^{[2]}$ and organic thin film solar cells ${ }^{[3]}$ are promising in terms of low-cost production of the devices. The organic semiconductors applicable for so-called "Printed Electronics" are required to have some properties such as high solubility into common organic solvents, spontaneous alignment of molecules in the solvent evaporation to form a film on substrate as well as the fast carrier mobility. Therefore, a self-assembling nature of molecules should be a profoundly related and attractive property for that type of organic semiconductors. This background has made it so interesting to study "organic semiconductors with mesogenicity" because all these requirements are in fact, facilitated properties in liquid crystalline materials. The discovery of fast carrier mobility in mesophase comparable to that of a-silicon $\left(>10^{-1} \mathrm{~cm}^{2} \mathrm{~V}^{-1} \mathrm{~s}^{-1}\right)^{[4]}$ where the molecules, more or less, are mobile and/or being fluctuated as a dynamic state of matter, have cast a great impact to the research field of liquid crystals to give "liquid crystalline semiconductor" or "mesophase semiconductor" ${ }^{[5]}$. However, such dynamic state of molecularly ordered materials have never led to the faster mobility than those of poly-crystalline and single crystalline thin films of organics such as pentacene ${ }^{[6]}$, rubrene ${ }^{[7]}$ and diphenylanthracene ${ }^{[8]}$, though these show the far lower solubility into organic solvents.

On the other hand, it is well-known that the typical molecular shapes of mesogens are of "rod-like (calamitic) and "disc-like"(discotic) and then, the smectic layered and molecularly stacked columnar structures are essentially important

Emerging Liquid Crystal Technologies VI, edited by Liang-Chy Chien, Hiroshi Yokoyama,

Proc. of SPIE Vol. 7955,795505 - @ 2011 SPIE · CCC code: 0277-786X/11/\$18 · doi: 10.1117/12.873717

Proc. of SPIE Vol. 7955 795505-1 
orderings of molecules, respectively, as charge transport materials by an electronic process. In particular, columnar structure is the similar motif to quasi-one-dimentional conductors of arenes and metal complexes ${ }^{[9]}$ in which charges on molecules are likely to transport along the axis of stacking molecules. This is essentially good for electronic hopping process for disordered states of matter, even though the disordered molecular systems are made with an anisotropic order in the aggregation. Therefore, this is well understood in a theoretical aspect described by classical Marcus theory of charge transfer ${ }^{[10]}$, meaning the single process of charge transport is an electronic charge transfer between two molecules and the hopping rate, $k$ is described as a following equation,

$$
k=\left(4 \pi^{2} / h\right) \tau^{2}\left(4 \pi \lambda \mathrm{k}_{\mathrm{B}} \mathrm{T}\right)^{-0.5} \exp \left(-\lambda / 4 \mathrm{k}_{\mathrm{B}} \mathrm{T}\right)
$$

where $\tau, \lambda, h, \mathrm{k}_{\mathrm{B}}$ and $\mathrm{T}$ are the transfer integral, reorganization energy, Planck constant, Boltzmann constant and temperature, respectively. The transfer integral is a function of interactions between HOMOs of the molecules for hole and LUMOs for electron transports, respectively ${ }^{[11]}$. The transfer integral, thus, is an important factor for charged carrier mobility in molecular aggregations and a certain length of successive hopping of electron is necessary for high charged carrier mobility as a macroscopic property, which have to be formed in the time scale of pico to nano second order because the time scale of charge hopping between two molecules takes place in the pico second order. This implies that molecular fluctuations in mesophase, more or less, directly relate to the charge hopping efficiency and in the case of the discotic liquid crystalline semiconductors, the molecular displacement to the lateral direction for the columnar axis and a conformational distribution around the columnar axis by rotational fluctuations are crucial for the effective charge hopping along the columnar axis as well as the periodic distance of molecular stacks ${ }^{[12]}$. Therefore, the dynamic aspects of mesophase should be considered for more efficient charge transport in mesophase and it could be controlled by way of modification of intermolecular interactions in the attractive and repulsive points of view to attain the higher mobility of charged carriers ${ }^{[13]}$.

Recently, Iino et al. found that $1,4,8,11,15,18,22,25$-octaoctylphthalocyanine $\left(\mathrm{C} \mathrm{PcH}_{2}\right)$ exhibits an ambipolar nature for the mobility in the hexagonal disordered columnar $\left(\mathrm{Col}_{\text {hd }}\right)$ mesophase, while phthalocyanine $(\mathrm{Pc})$ is recognized as a p-type semiconductor ${ }^{[14]}$. Also the mobilities are rather fast in the order of $10^{-1} \mathrm{~cm}^{2} \mathrm{~V}^{-1} \mathrm{~s}^{-1}$, exhibiting fieldindependent property and a slight or non-dependency on temperature which are of typical for liquid crystalline semiconductors ${ }^{[15]}$.

When one sees the history of studies on liquid crystalline Pcs, two types of mesogens could be recognized as a discotic mesogen and those are depicted in Fig.1. It is quite interesting to see that such a fast mobility is obtained for the type B Pc, which is at least comparable to those of the type A. In addition, one can see a contrast between the Type A

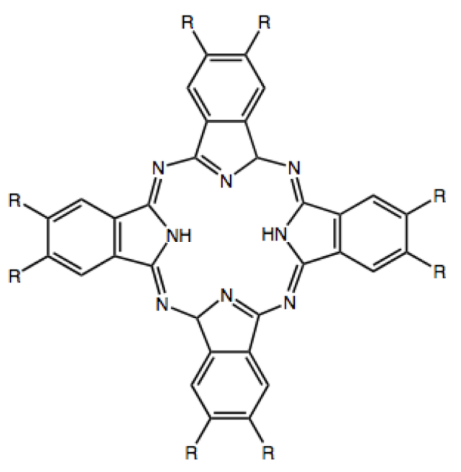

Type A

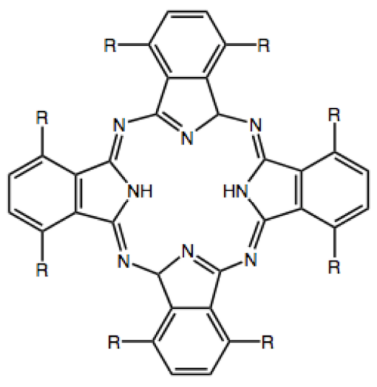

Type B

$$
\begin{array}{lll}
R=\mathrm{C}_{n} \mathrm{H}_{2 n+1} & n=6 & \mathrm{C} \mathrm{PCH}_{2} \\
n=8 & \mathrm{C} \mathrm{PcH}_{2}
\end{array}
$$

Figure 1: Two types of phthalocyanine discotic liquid crystals. Type A is a derivative of which alkyl or alkoxy chains attach to the $2,3,9,10,16,17,23$ and 24 positions of phthalocyanine ring and Type B is a derivative with alkyl chains attached at the 1, 4, 8, $11,15,18,22$ and 25 ones. 
and B Pcs for the mobilities measured by a Time-Of-Flight (TOF) ${ }^{[16]}$ and Pulse-Radiolysis Time-Resolved Microwave (PR-TRMC) ${ }^{[17]}$ techniques, which could determine the drift and intrinsic mobilities to be $2.6 \times 10^{-3} \mathrm{~cm}^{2} \mathrm{~V}^{-1} \mathrm{~s}^{-1}$ and 0.2 $\mathrm{cm}^{2} \mathrm{~V}^{-1} \mathrm{~s}^{-1}$, respectively.

Considering that the much more bulkiness of alkyl chains in $\mathrm{C} 8 \mathrm{PcH}_{2}$ is derived from the attaching positions of alkyl chains to a Pc ring, it is reasonable to imagine that a steric repulsive interaction arises against the tight stacking of molecules when they form a columnar structure. In fact, the XRD patterns of $\mathrm{Col}_{\mathrm{h}}$ mesophase never show the correspondent reflection at 20-28 ${ }^{\circ}(3.3-3.6 \AA)$, indicating a disordered column ${ }^{[18]}$ and the $\mathrm{Co}_{\text {hd }}$ mesophase of the type A Pc homologues exhibits the higher thermal stability than those of the type B homologues ${ }^{[19]}$.

In this communication, the surprising results on the carrier mobility of the hexyl homologue $\left(\mathrm{C}^{2} \mathrm{PcH}_{2}\right)$ are shown where the drift mobilities of hole and electron exhibit to be higher to $0.3-0.4 \mathrm{~cm}^{2} \mathrm{~V}^{-1} \mathrm{~s}^{-1}$, and these could be determined even in the crystalline phase to be in $10^{-1} \sim 1.4 \mathrm{~cm}^{2} \mathrm{~V}^{-1} \mathrm{~s}^{-1}$ for hole and $0.5 \mathrm{~cm}^{2} \mathrm{~V}^{-1} \mathrm{~s}^{-1}$ for electron. The mesomorphism of $\mathrm{C} \mathrm{PcH}_{2}$ was already reported to exhibit only one mesophase assigned to be of a $\mathrm{Col}_{h d}$ type ${ }^{[20]}$.

\section{EXPERIMENTAL}

\subsection{Synthesis and purification of the compound}

The compound was synthesized according to the literature with slight modifications as shown in Fig. $2^{[20]}$ and fully purified by column chromatography (Silica-gel with toluene as eluent) followed by the repetitive recrystallization from toluene - methanol (1:2) solution.

\subsection{Characterization of mesomorphism}

The phase transition temperatures and enthalpy changes were measured by differential scanning calorimetry (DSC, TA instrument DSC2920) and from microscopic observations of the optical textures (Olympus BH2 and Mettler FP90 hot stage). The mesophases were identified by X-Ray diffraction measurements in the temperature range of the mesophase using a Rigaku RINT 2500 HF equipped with a hand-made hot stage.

\subsection{Charged carrier mobility of mesophase}

The mobility in mesophase was determined by Time-Of-flight (TOF) technique as schematically shown in Fig.3. The cell is of sandwich-type consisting of two ITO-coated glass plates as the electrodes (effective area of the electrode : 5 x 5 $\mathrm{mm}^{2}$ ) and polyimide film (Toray Kapton with $12.5 \mu \mathrm{m}$ ) as spacer. The actual cell gaps were evaluated by an interference technique of light transmittance The sample was injected by capillarity action at the temperature above the
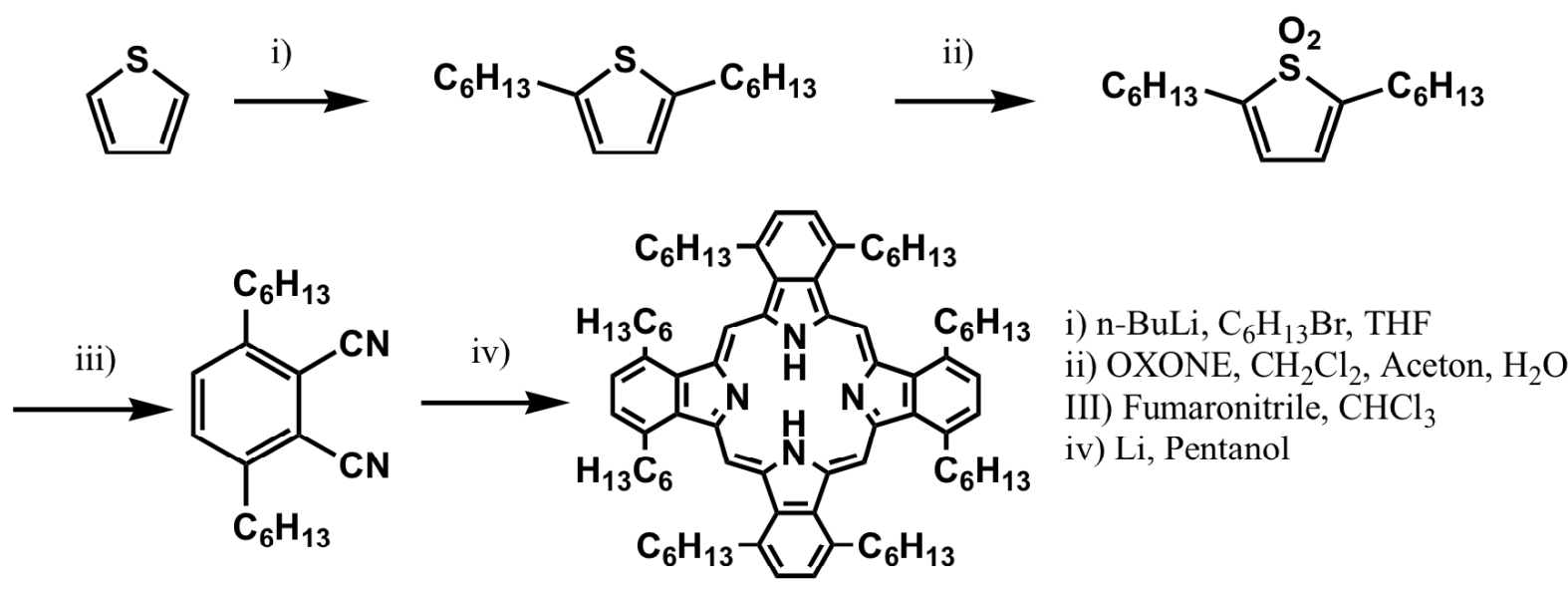

Figure 2: Synthetic route of $\mathrm{C} \mathrm{PcH}_{2} \cdot{ }^{[20]}$ Purifications of the final product are so important to obtain clear decay curves of the transient photocurrent in TOF measurements and the reproducibility. 


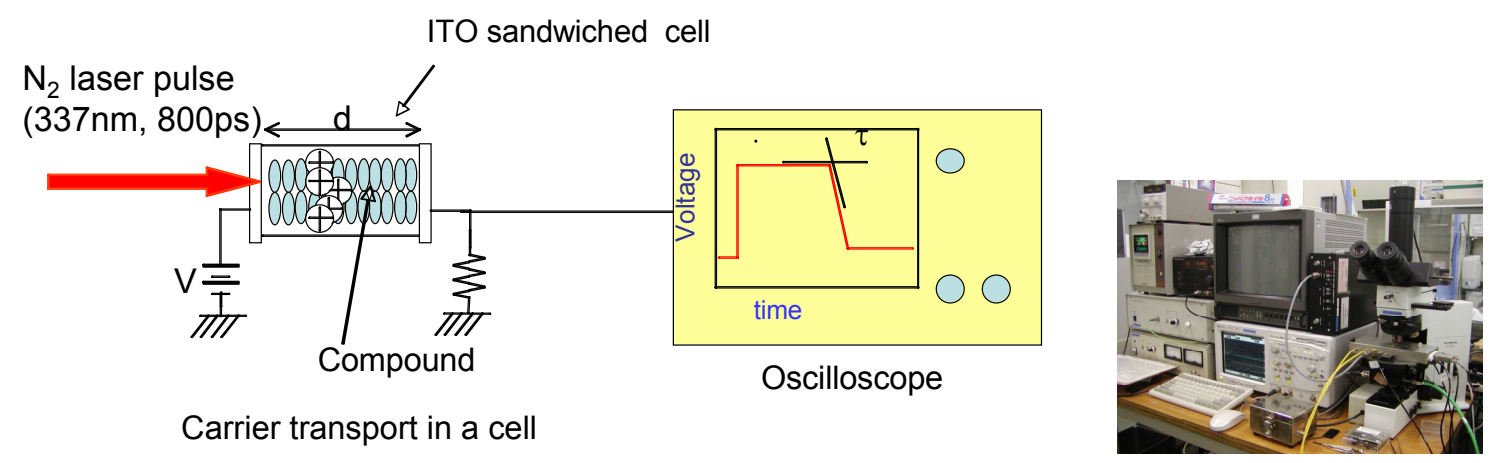

Figure 3 : A schematic drawing of Time-Of-Flight (TOF) apparatus equipped with a polarized microscope.

isotropisation one. A $\mathrm{N}_{2}$-pulsed laser $(337 \mathrm{~nm}, 800 \mathrm{ps}$ ) was used for the photocarrier generation. The DC bias was applied by batteries. The transient photocurrents were detected by a digital oscilloscope (HP, infinum) with the help of a wide band preamplifier (NF electronics instruments, BX-31A). The mobility, $\mu$ was calculated by the equation below,

$$
\mu=d^{2} / V \tau_{s}
$$

where $d, V$ and $\tau_{s}$ are sample thickness, applied bias and the transit time, respectively.

\section{RESULTS AND DISCUSSION}

\subsection{Mesomorphism}

Fig. 4 shows the DSC curves and XRD patterns of the $\mathrm{Col}_{h}$ mesophase for $\mathrm{C} \mathrm{PcH}_{2}$ as the essential properties as a mesophase material. This compound exhibits two endo- and exo-thermic peaks on both heating and cooling runs, meaning that the phase transitions of clearing and melting are of enantiotropic. The crystal-mesophase phase transition takes place at $161{ }^{\circ} \mathrm{C}$ and the clearing is seen at $170{ }^{\circ} \mathrm{C}$. An additional phase transition of crystal-crystal is observed at $-25{ }^{\circ} \mathrm{C}$. The XRD patterns at $165{ }^{\circ} \mathrm{C}$ confirm that the mesophase is assigned to be a $\mathrm{Col}_{h d}$ mesophase with a series of reflection peaks of which d-spacings are in the ratio of $1: 1 / \sqrt{3}: 1 / 2\left(\mathrm{~d}_{10}, \mathrm{~d}_{11}\right.$ and $\mathrm{d}_{20}$ of the hexagonal arrays of columns) accompanied with only a broad halo at around $2 \theta=20^{\circ}$ (ca. $4.5 \mathrm{~A}$ ) derived from the molten alkyl chains. The calculated lattice parameter, $a$ for the $\mathrm{Col}_{\text {hd }}$ mesophase is determined to be $20.9 \AA\left(162{ }^{\circ} \mathrm{C}\right)$ and this is a reasonable value for the estimated diameter of molecule (ca. $26 \AA$ with full-extended chains). These results are not incoincident with the published results by Cook et al. [18]
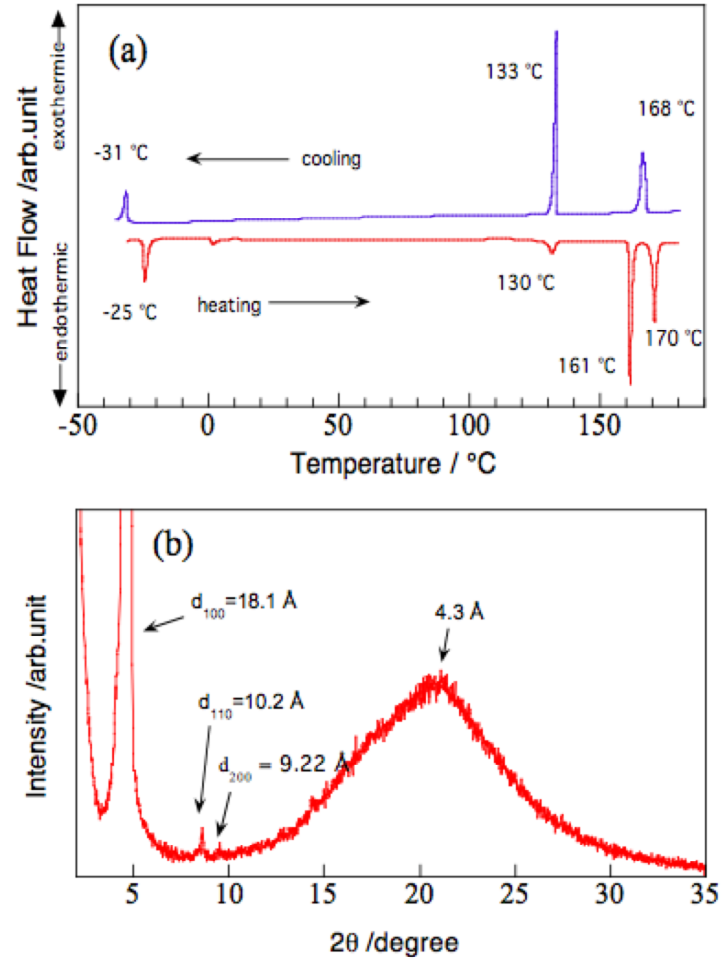

Figure 4: Results of DSC and XRD measurements for $\mathrm{C} \mathrm{PcH}_{2}$. (a) DSC curves (heating and cooling rates : $5^{\circ} \mathrm{C} \mathrm{min}^{-1}$ ). (b) an XRD pattern for the non-aligned sample at $160^{\circ} \mathrm{C}$. 
(a) hole at $165^{\circ} \mathrm{C}$
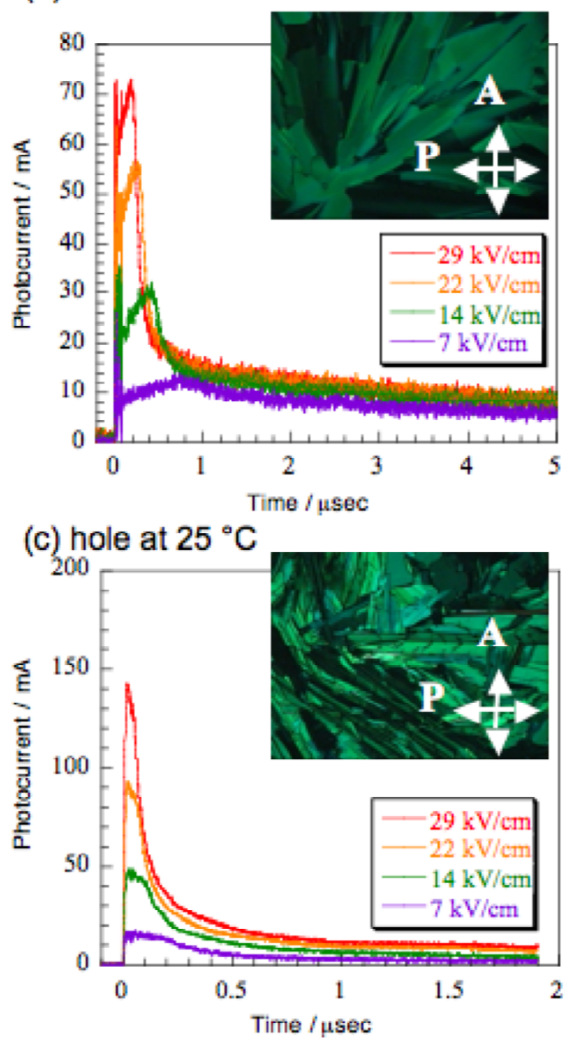

(b) electron at $165^{\circ} \mathrm{C}$

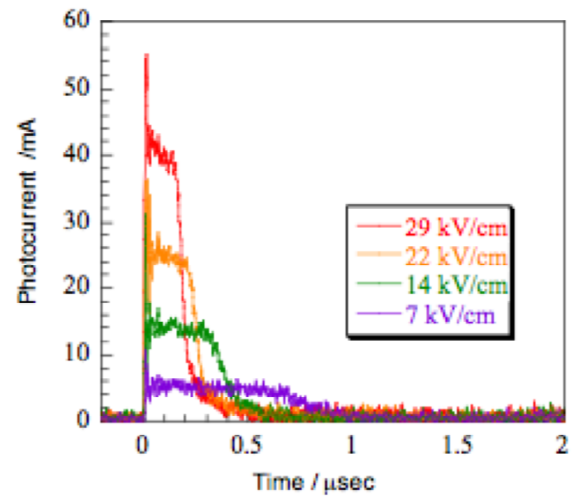

(d) electron at $25^{\circ} \mathrm{C}$

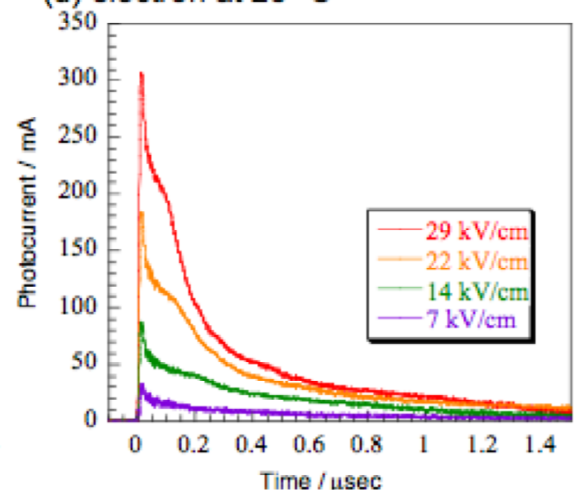

Figure 5: Transient photocurrent decay curves of $\mathrm{C} \mathrm{PcH}_{2}$ in $\mathrm{Col}_{\mathrm{hd}}$ mesophase $\left(160^{\circ} \mathrm{C}\right)$ for (a) hole and (b) electron and in the solid at $25^{\circ} \mathrm{C}$ for (c) hole and (d) electron. Optical textures observed for the cell under a crossed polarizers are shown for both phases.

\subsection{Carrier mobility}

Fig. 5 shows a typical decay curve of transient photocurrent (hole and electron) for the $\mathrm{Col}_{\mathrm{hd}}$ and crystalline phases and the optical textures of the cell used for the mobility measurements. Being so different from the spontaneous alignment behaviour of $\mathrm{C} \mathrm{PcH}_{2}$ that exhibits a strong tendency to form a homeotropic alignment (a face-on alignment to the substrate surface) for the $\mathrm{Col}_{\text {hd }}$ phase, any homeotropic domains was not observed in the poly-domain textures. Nevertheless, very clear decay curves were observed for both hole and electron transports, though the worse situation of decay curves could be recognized for the hole. The mobility is not dependent on the applied field in the range of $7 \sim 29$ $\mathrm{kV} \mathrm{cm}{ }^{-1}$. An ambipolar nature was evidenced also in $\mathrm{C} \mathrm{PcH}_{2}$ as the $\mathrm{C} 8 \mathrm{PcH}_{2}$ homologue exhibits.

In the $\mathrm{Col}_{\text {hd }}$ phase, the observed mobility is $0.2 \sim 0.3 \mathrm{~cm}^{2} \mathrm{~V}^{-1} \mathrm{~s}^{-1}$ as shown in Fig. 6 and mostly of temperature independent and interestingly, the hole mobility is lower than the electronic one. This is the opposite to the result for $\mathrm{C}_{8} \mathrm{PcH}_{2}$. On cooling step (the decay curves were measured at the steady state of temperature), the decay curves observed in the temperature range of crystal surprisingly exhibit quite clear ones by which one can easily determined the transit times, even though the optical texture is of poly-domain. As far as we have experienced for a variety of mesophase semiconductors, the crystallization of mesophase gives a poly-domain film to get the decay curves dispersive and consequently it is difficult to determine the transit time, even if a mono-domain state is observed for the mesophase by a polarized microscope.

For the crystalline phase, the hole mobility increases to $1.4 \mathrm{~cm}^{2} \mathrm{~V}^{-1} \mathrm{~s}^{-1}$ from $0.4 \mathrm{~cm}^{2} \mathrm{~V}^{-1} \mathrm{~s}^{-1}$, as the temperature goes down to $-15{ }^{\circ} \mathrm{C}$ from $140{ }^{\circ} \mathrm{C}$, while the electron mobility is in almost steady level of $0.4 \mathrm{~cm}^{2} \mathrm{~V}^{-1} \mathrm{~s}^{-1}$ in the same temperature range. The hole mobility is larger than electron one in the crystalline solid phase and the temperature dependence is not similar to each. These features of mobility behaviour were not reported for $\mathrm{C} \mathrm{PcH}_{2}$ and this indicates 


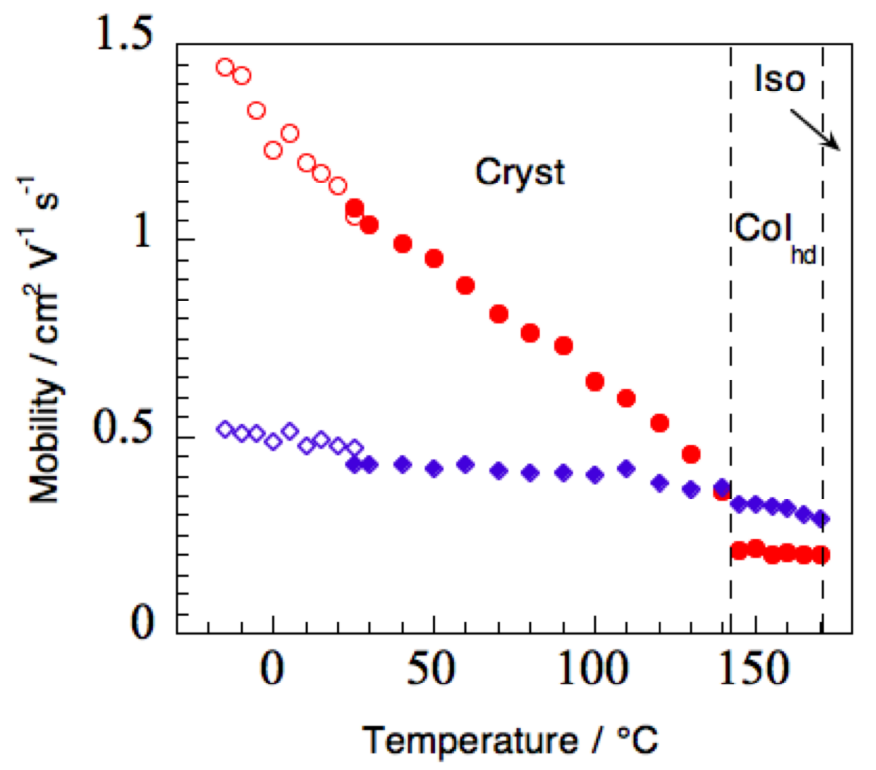

Figure 6 : Temperature dependence of hole (circle) and electron (square) mobilities of $\mathrm{C} \mathrm{PcH}_{2}$. Filled and open symbols are for the measurements on cooling and heating steps, respectively. The measurements were carried out at the steady state of temperature.

that the crystallization process on cooling from the molten state is different in these two homologues. In additon, optical texture formation of the $\mathrm{Col}_{\text {hd }}$ phase exhibits something strange ${ }^{[21]}$, indicating that this $\mathrm{Col}_{\text {hd }}$ mesophase is not of a non-

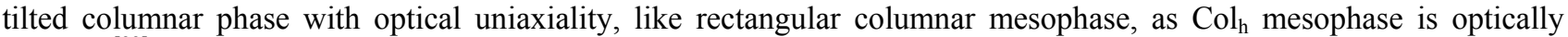
uniaxial ${ }^{[22]}$.

The hole and electron mobilities in the $\mathrm{Col}_{\mathrm{hd}}$ mesophase are comparable to those of $\mathrm{C} \mathrm{PcH}$. This would be a reasonable, considering the similarity in molecular order for both $\mathrm{Col}_{\text {hd }}$ mesophases as inferred from the XRD patterns for a non-aligned samples. On the other hand, the single crystal XRD studies were carried out for $\mathrm{C}^{\mathrm{Pc}} \mathrm{H}_{2}$ in the early days of chemical studies on this type of mesogenic Pc to show an extraordinary situation for the stacking manner of molecules ${ }^{[23]}$, where one can see a far long distance $(8 \sim 9 \AA)$ for the periodical stacking along the $c$ axis. On this point of view, the fact that such a fast mobility of charged carriers is observed for the crystalline phase is so strange. However, the Pc planes are possibly so close to each for contacting at the edge of Pc rings. In fact, one can see the overlapping of benzo ring along the $a$-axis. This indicates that in the case of $\mathrm{C}_{6} \mathrm{PcH}_{2}$, the intercolumnar distance in the Col $\mathrm{Ch}_{\text {hesophase }}$ is rather short to a well-defined orientation of columns due to the position of alkyl-attaching site in addition to the shorter chains. In fact, the important feature in XRD results for the $\mathrm{Col}_{\mathrm{hd}}$ mesophse of $\mathrm{C} \mathrm{PcH}_{2}$ is that the corresponding Pc derivative of type A which alkyl chains attach at the 2, 3, 9, 10, 16, 17, 23 and 24 sites of a Pc ring exhibits a slightly larger lattice parameter $a(22.5 \AA)$ probably due to the typical positions as the peripheral part of central core. ${ }^{[19]}$ The shorter intercolumnar distance in the $\mathrm{Col}_{\mathrm{h}}$ mesophase of $\mathrm{C} \mathrm{PcH}_{2}$ would be better for the subsequent charge transport in the lateral direction to the columnar axis.

\section{CONCLUSION}

It was found that $\mathrm{C}_{6} \mathrm{PcH}_{2}$ exhibit fast mobility with ambipolar carrier transport in both $\mathrm{Col}_{\text {hd }}$ mesophase and crystalline solid phase to be in the order of $10^{-1} \mathrm{~cm}^{2} \mathrm{~V}^{-1} \mathrm{~s}^{-1}$ and of $10^{-1}$ to $1.4 \mathrm{~cm}^{2} \mathrm{~V}^{-1} \mathrm{~s}^{-1}$, respectively. These could be obtained for poly-domain film where the molecules are aligned not in the homeotropic way for the mesophase. These results may imply it is possible to have a novel design concept of liquid crystalline semiconductors which could have efficient charge transport not only along the columnar axis, but also not along it for discotics. Also considering the characteristic 
properties of Pcs as practical pigments and dyes, $\mathrm{C} 6 \mathrm{PcH}_{2}$ is a good candidature as a solution-processable organic semiconductor for the practical use. Recent results for a simple bulk-heterojunction cell with $\mathrm{C}_{6} \mathrm{PcH}_{2}$ and $\mathrm{PCBM}$ exhibits a fantastic performance of $3.1 \%$ for the power conversion efficiency with $>70 \%$ for the external quantum efficiency at the Q-band ${ }^{[24]}$ and this also may indicate the peculiarity of $\mathrm{C}^{2} \mathrm{PcH}_{2}$ as organic semiconductors.

\section{ACKNOWLEDGMENTS}

This study was carried out by a financial support, in part by Grants-in-Aid for Scientific Research from the Ministry of Education, Culture, Sports, Science and Technology, Japan, the Japan Society for the Promotion of Science (JSPS) Bilateral Joint Projects (Japan - China) and Osaka University Frontier Research Center and the 8 Global Center of Excellence (Global COE) Program “Center for Electronic Devices Innovation” at Osaka University.

\section{REFERENCES}

[1] a) J. Zaumseil, R. H. Friend and H. Sirringhaus, Nat. Mater., 2006, 5, 69 ; b) D. C. Muller, A. Falcou, N. Reckefuss, M. Rojahn, V. Wlederhirm, P. Rudati, H. Frohne, O. Nuyken, H. Becker and K. Meerhotz, Nature (London), 2003, 421, 829 .

[2] a) J. Zaumseil and H. Sirringhaus, Chem. Rev., 2007, 107, 1296 ; b) A. R. Murphy and J. M. J. Fréchet, Chem. Rev., 2007, 107, 1066 ; c) O. Bunk, M. M. Nielsen, T. I. Solling, A. M. van de Craats and M. J. Stutzmann, J. Am. Chem. Soc., 2003, 125, 2252.

[3] a) J. Peet, A. J. Heeger, and G. C. Bazan, Acc. Chem. Res., 2009, 42, 1700 ; b) J. -L. Brédas, J. E. Norton, J. Cornil and V. Coropceanu, Acc. Chem. Res., 2009, 42, 1691 ; c) C. J. Brabec and J. R. Durant, MRS Bull., 2008, 33, 670.

[4] D. Adam, P. Schuhmacher, J. Simmerer, L. Häussling, K. Siemensmeyer, K. H. Etzbach, H. Ringsdorf and D. Haarer, Nature, 1994, 371, 141.

[5] a) W. Pisula, M. Zorn, J. -Y. Chang, K. Müllen and R. Zentel, Macromol. Rapid Commun., 2009, 30, 1179; b) M. Funahashi, Polym. J., 2009, 41, 459 ; c) S. Sergeyev, W. Pisula and Y. H. Geerts, Chem. Soc. Rev., 2007, 36, 1902 ; d) S. Laschat, A. Baro, N. Steinke, F. Giesselmann, C. Hägele, G. Scalia, R. Judele, E. Kapatsina, S. Sauer, A. Schreivogel and M. Tosoni, Angew. Chem. Int. Ed., 2007, 46, 4832 ; e) Y. Shimizu, K. Oikawa, K. Nakayama and D. Guillon, J. Mater. Chem., 2007, 17, 4223 ; f) J. Hanna, Opto-Electron. Rev., 2005, 13, 295; g) M. O’Neill and S. M. Kelly, $A d v$. Mater., 2003, 15, 1135.

[6] a) O. D. Jurchescu, M. Popinciuc, B. J. van Wees, and T. T. M. Palstra, Adv. Mater., 2007, 19, 688; b) O. D. Jurchescu, J. Baas and T. T. M. Palstra, Appl. Phys. Lett., 2004, 84, 6883061.

[7] a) M. Yamagishi, J. Takeya, Y. Tominari, Y. Nakazawa, T. Kuroda, S. Ikehata, M. Uno, T. Nishikawa, T. Kawase, Appl. Phys. Lett. 2007, 90, 182117; b) V. C. Sundar, J. Zaumseil, V. Podzorov, E. Menard, R. L. Willett, T. Someya, M. E. Gershenson, J. A. Rogers, Science 2004, 303, 1644; c) V. Podzorov, E. Menard, A. Borissov, V. Kiryukhin, J. A. Rogers, M. E. Gershenson, Phys. Rev. Lett., 2004, 93, 086602.

[8] A. Kumar Tripathy, M. Heinrich, T. Siegrist and J. Pflaum, Adv. Mater., 2007, 19, 2097.

[9] P. W. Anderson, P. A. Lee and M. Saitoh, Solid State Commun., 1973, 13, 595.

[10] R. A. Marcus, Rev. Mod. Phys., 1993, 65, 599.

[11] V. Balzani, A. Juris, S. Campagna and S. Serroni, Chem. Rev., 1996, 96, 759.

[12] a) X. Feng, V. Marcon, W. Pisula, M. R. Hansen, J. Kirkpatrick, F. Grozema, D. Andrienko, K. Kremer and K. Müllen, Nat. Mater., 2009, 8, 421; b) V. Lemaur, D. A. da Silva Filho, V. Coropceanu, M. Lehmann, Y. Geerts, J. Piris, M. G. Debije, A. M. van de Craats, K. Senthilkumar, L. D. A. Siebbeles, J. M. Warman, J.-L. Brédas and J. Cornil, J. Am. Chem. Soc., 2004, 126, 3271.

[13] a) Y. Olivier, L. Muccioli, V. Lemaur, Y. H. Geerts, C. Zannoni and J. Cornil, J. Phys. Chem. B, 2009, 113, 14102 ; b)K. Senthilkumar, F. C. Grozema, F. M. Bickelhaupt and L. D. A. Siebbeles, J. Chem. Phys., 2003, 119, 9809.

[14] H. Iino, Y. Takayashiki, J. Hanna and R. J. Bushby, Jpn. J. Appl. Phys., 2005, 44, L1310; H. Iino, J. Hanna, R. J. Bushby, B. Movaghar, B. J. Whitaker and M. J. Cook, Appl. Phys. Lett., 2005, 87, 132102.

[15] K. J. Donovan and T. Kreouzis, J. Appl. Phys., 2000, 88, 918.

[16] C. Deibel, D. Janssen, P. Heremans, V. De Cupere, Y. Geerts, M. L. Benkhedir and G. J. Adriaenssens, Org. Electron., 2006, 7, 495.

[17] J. M. Warman, M. P. de Haas, G. Dicker, F. C. Grozema, J. Piris and M. G. Debije, Chem. Mater., 2004, 16, 4600. 
[18] M. J. Cook, S. J. Cracknell and K. J. Harrison, J. Mater. Chem., 1991, 1, 703.

[19] M. K. Engel, P. Bassoul, L. Bosio, H. Lehmann, M. Hanack and J. Simon., Liq. Cryst., 1993, 15, 709.

[20] a) J. C. Swarts, E. H. G. Langner, N. Krokeide-Hove and M. J. Cook., J. Mater. Chem., 2001, 11, 434 ; b) M. J. Cook, M. F. Daniel, K. J. Harrison, N. B. McKeown and A. J. Thomson, J. Chem. Soc., Chem. Commun., 1987, 1086.

[21] H. Yoshida, Y. Miyake, T. Hori, N. Yamasaki, A. Fujii, Y. Shimizu and M. Ozaki, unpublished data.

[22] S. Chandrasekhar, in Handbook of Liquid Crystals, Vol. 2B (Eds: D. Demus, J. Goodby, G. W. Gray, H. -W. Spiess, V. Vill), Wiley-VCH, Weinheim, Germany, 1998, Ch. VIII.

[23] I. Chambrier, M. J. Cook, M. Helliwell and A. K. Powell, J. Chem. Soc., Chem. Commun., 1992, 444.

[24] T. Hori, Y. Miyake, N. Yamasaki, H. Yoshida, A. Fujii, Y. Shimizu and M. Ozaki, Appl. Phys. Express, 2010, 3, 101602 .

*yo-shimizu@aist.go.jp; phone 8172 751-9525; fax 8172 751-9628

*ozaki@eei.eng.osaka-u.ac.jp; phone 816 6879-7757; fax 816 6879-7774 